\section{Treatment of Hypoadrenalism}

Sir,-Sir Derrick Dunlop (October 12 , p. 887) and the writer of your leading article in the same issue (p. 882) both recommend cortisone acetate plus fludrocortisone as adequate treatment for patients suffering from Addison's disease and for those whose adrenal glands have been removed surgically.

The human adrenal cortex secretes hydrocortisone (cortisol) and not cortisone. The latter is biologically inactive. Cortisone is used as replacement therapy because it is easier and therefore cheaper to manufacture and is normally effective because it is converted to hydrocortisone in its passage through the liver. Under certain circumstances-namely, liver disease - the conversion of cortisone to hydrocortisone is impaired and satisfactory replacement is not obtained with the recommended dose of cortisone (25$37.5 \mathrm{mg}$.) nor with amounts up to $75 \mathrm{mg}$ daily. The administration of tablets of hydrocortisone $20 \mathrm{mg}$. in the early morning and $10 \mathrm{mg}$. at mid-day, simulating the normal diurnal rhythm of hydrocortisone secretion, will be noted by these patients to be accompanied by a greatly increased feeling of well-being. Three of our patients adrenalectomized for Cushing's syndrome, who were requiring $75 \mathrm{mg}$. of cortisone acetate daily, plus 0.1 or 0.2 mg. of fludrocortisone, and who did not feel well on this dose, were found to have moderately increased retention of bromsulphthalein (B.S.P.) at $\mathbf{4 5}$ minutes. They were greatly improved by transfer to $30 \mathrm{mg}$. of hydrocortisone. Others with normal B.S.P. tests whose treatment was altered from cortisone to hydrocortisone without them being told have remarked spontaneously about how well they were now feeling.

Despite its slightly higher cost it would seem that hydrocortisone B.P. is to be preferred to cortisone acetate as the natural glucocorticoid replacement therapy in patients with loss of adrenal function. Fludrocortisone is also given in a dose of $0.1 \mathrm{mg}$. to replace aldosterone.-I am, etc.,

E. J. Ross.

University College Hospital Medical School,

London W.C.1.

\section{Addiction to Amphetamines}

SIR,-It is a sad reflection on our corporate responsibilities as physicians that at this time Miss M. C. Paterson (September 14, p. 684) should find it necessary to express the continued and growing anxiety of workers in the many fields regarding the extent of habituation to amphetamines. The matter has indeed been investigated and received serious consideration ranging from Connell's ${ }^{1}$ description of amphetamine psychosis to your recent leading article (August 17, p. 399), yet the problem continues to grow.

In a survey conducted by general practitioners ${ }^{2}$ nearly one in five of those receiving these drugs were shown to be habituated, and those at greatest risk appeared to be the very patients for whom amphetamines are most commonly prescribed. Apart from the doubtful therapeutic necessity for these drugs there appears at times to be a carelessness in their prescription which amounts to real negligence.

If we are to avoid the ogre of ministerial direction we must accept full responsibility for our prescribing habits. How long is it since most of us were faced with a case of morphine addiction ?-the rarity of the condition is not due to any lack of addictive properties but to the responsibility which is usually exercised in prescribing the drug.

The amphetamines deserve equal respect, and until they receive it the courts rather than physicians will exercise control.-I am, etc.,

\section{Department of Psychiatry Columbia University College of Physicians and Surgeons. \\ REFERENCES \\ 1 Connell, P. H., Amphetamine Psychosis, 1958 Maudsley Monographs, No. 5. Chapman and Hall, London. \\ 2 Brandon, S., and Smith, D., J. Coll. gen. Practit. 1962, 5, 603 .}

\section{Toxicity of Acetazolamide}

SIR,-Your article on anticonvulsants (October 12, p. 919) in the "To-day's Drugs" series was a welcome review of an important topic, which will have been widely read. The statement made in that article that major toxic effects have not been observed with acetazolamide should not go unchallenged. Mention should be made of the renal complications of treatment with this drug, which is also used as a long-term measure in glaucoma and even heart failure.

The substance is chemically a heterocyclic sulphonamide. Crystals, resembling those obtained by recrystallization of acetazolamide in acid solution, have been demonstrated at necropsy in the renal tubules of a man treated with the drug 24 days earlier. ${ }^{2}$ Gill and Vermeulen, discussing a possible association between urolithiasis and treatment with " diamox" (acetazolamide), reviewed reported cases and designed animal experiments to test it. They reported marked crystalluria in rats given acetazolamide, but were only able to induce renal calculus formation when in addition the urinary tract was subjected to operative insult or a foreign body was placed in the bladder.

Becker and Middleton," Scheie," and Persky et al." all reported renal complications associated with acetazolamide therapy. Barraquer and Escribano described typical renal colic in 30 patients among 300 with glaucoma treated in this way. In this country Yates-Bell ${ }^{\prime}$ published a case with bilateral non-calculous ureteric obstruction attributed to the drug, relieved by ureteric catheterization. He also discussed a similar patient, who died with anuria, reported by Dr. L. H. Worth at the Royal Society of Medicine on February 28 , 1956, but not published. Davies described two patients, one of whom had repeated episodes of renal colic closely related to administration of the drug. This man, who had unilateral suppression of urine on one of these occasions, was relieved by ureteric catheterization. Although these complications of treatment may be infrequent. they need to be recognized as such not only because they can be serious but also to prevent continued administration of the offending agent.-I am, etc.,

\section{Wynne Davies.}

Barnt Green, Worcs.

REFERENCES

Glushien, A. S., and Fisher, E. R., J. Amer. med. Ass. 1956, 160,204

med. Ass. 1956, 160, 204. $C$ W. $1962,88,103$.

Becker. B. and Middleton, W. $\mathbf{H}$, Ophthal., 1955, 54, 187.

Scheie, H. G., Amer. J. Ophthal 1955, 39, 887. Persky, L.. Chambers, D. and Potts, A. 887. Amer. med. Ass., 1956, 161, 1625.

- Barraquer, J., and Escribano, J., Rev. clin. esp. $1957,64,310$.

Yates-Bell, J. G., Brit. med. J., 1958, 2, 1392.

- Davies, D. W., ibid., 1959, 1. 214.

\section{Urethral Diverticula in Women}

Sir,-Dr. Anthony Phillips, commenting on his interesting case of diverticulum of the female urethra containing multiple calculi (October 12, p. 917), says that it would appear likely that this lesion is acquired and not congenital, because 80 to $90 \%$ of the reported cases occurred in parous women.

Of the three possible causes of urethral diverticulum-infection, trauma, and congenital abnormality-infection has in the past been considered by many authors to be the most likely. However, there is usually no history of a previous parurethral abscess even when the sac of the diverticulum is large, and, although the female urethra is frequently infected on account of its complicated glandular structure and its exposed position, diverticula are relatively rare.

Trauma resulting from difficult childbirth, urethral instrumentation, or passage of a calculus have been suggested as possible aetiological factors, ${ }^{1}$ but there is seldom any. history of direct trauma apart from child-bearing, and this condition is much more likely to cause dislocation of the urethra from behind the symphysis pubis than the characteristic sac of a urethral diverticulum with its narrow neck, muscular wall, and epithelial lining.

The third possibility, that the diverticulum is due to a congenital abnormality, seems to fit the available facts best. Diverticula are situated behind the middle third of the urethra near the insertion of the pubo-coccygeus in a remarkably constant manner. ${ }^{2}$ The sac is sometimes lined by squamous or columnar epithelium which can hardly have come secondarily from the urethral transitional epithelium. Also, those occasional specimens which are seen in very young children, ${ }^{3}$ or into which an ectopic ureter opens, can only be congenital in origin.

It is likely, therefore, that diverticula of the female urethra, like those of the bladder and colon, are congenital in 